\title{
Eficácia e toxicidade da hidroxiuréia em crianças com anemia falciforme
}

\section{Effectiveness and toxicity of hydroxyurea in children with sickle cell anemia}

Michelle C. Silva ${ }^{1}$

Eliana L. T. Shimauti ${ }^{2}$

\begin{abstract}
A anemia falciforme é uma doença genética caracterizada pelo alto índice de morbimortalidade, considerada como a mais grave entre as doenças falciformes. As opções terapêuticas mais eficazes atualmente disponíveis para tratamento desta hemoglobinopatia são transplante de medula óssea (TMO) e hidroxiuréia (HU). $O$ TMO apesar de ser a medida curativa é considerado de alto risco por apresentar diversos graus de complicações e significativo nível de mortalidade. O uso de $\mathrm{HU}$ em crianças portadoras de anemia falciforme tem proporcionado redução de complicações clínicas e aumento significativo na expectativa de vida, por promover elevação dos níveis de hemoglobina fetal, da concentração de hemoglobina e do VCM, bem como redução da hemólise e de eventos vaso-oclusivos. Desse modo, a HU é considerada como melhor opção terapêutica atualmente disponível. Porém, por ser apontada como droga potencialmente carcinogênica, há questionamentos quanto aos benefícios e toxicidades quando utilizada por longo período. Este trabalho teve como proposta, avaliar por meio da revisão literária, os riscos, benefícios e efeitos adversos da hidroxiuréia em crianças. Rev. bras. hematol. hemoter. 2006;28(2):144-148.
\end{abstract}

Palavras-chave: Anemia falciforme; hidroxiuréia; população pediátrica.

\section{Introdução}

Anemia falciforme é uma doença genética determinada pela homozigose da hemoglobina S (Hb SS) caracterizada por anemia hemolítica crônica, susceptibilidade aumentada às infecções e episódios vaso-oclusivos repetidos, associados às lesões orgânicas crônicas e crises dolorosas agudas. Entre as doenças falciformes, esta é a forma que apresenta maior gravidade clínica e hematológica além de ser a mais prevalente. ${ }^{1,2,3}$ Estima-se que no Brasil há mais de 2 milhões de portadores do gene da $\mathrm{Hb} \mathrm{S}$; desses, mais de 8 mil apresentam forma grave (SS). Estima-se ainda que haja setecentos a mil novos casos anuais de doenças falciformes, sendo, portanto, consideradas como importante problema de saúde pública. ${ }^{3,4}$

O gene S é originário da África e apresenta-se amplamente distribuído em todos os continentes, atingindo alta prevalência em população negra e seus descendentes. No
Brasil, a distribuição da Hb S é heterogênea, sendo mais freqüente em regiões Norte e Nordeste. Esta variação regional está relacionada com a contribuição dos grupos étnicos formadores. ${ }^{2,5}$

Di Nuzzo \& Fonseca ${ }^{6}$ relatam que a porcentagem de mortalidade entre as crianças menores de 5 anos com anemia falciforme atinge de $25 \%$ a $30 \%$. Esses dados enfatizam a importância da realização de diagnóstico precoce e instituição da terapia adequada para promover a redução nesse índice de morbimortalidade.

As opções terapêuticas mais eficazes atualmente disponíveis para tratamento desta hemoglobinopatia são transplante de medula óssea (TMO) e a hidroxiuréia (HU). O TMO, apesar de ser a medida curativa, quando dispõe de um doador compatível, é considerado de alto risco por apresentar grande índice de complicações e mortalidade. ${ }^{7,8,9}$

Vários estudos têm demonstrado que a concentração elevada de $\mathrm{Hb}$ Fetal ( $\mathrm{Hb} \mathrm{F}$ ) em pacientes com anemia

${ }^{1}$ Farmacêutica-Bioquímica aluna do Curso de Especialização em Análises Clínicas da Universidade Estadual de Maringá (UEM) - PR.
${ }^{2}$ Prof ${ }^{a}$ do Departamento de Análises Clínicas (DAC) da Universidade Estadual de Maringá (UEM) - PR.

Correspondência: Eliana L.T. Shimauti

Universidade Estadual de Maringá - Departamento de Análises Clínicas

Av. Colombo, 5790, zona 07

87020-900 - Maringá -PR

Tel: (44) 3261-4800

E-mail: eltshimauti@uem.br 
falciforme é particularmente útil na proteção contra os eventos de eritrofalcização e vaso-oclusão, e indicam ser um fator moderador das conseqüências clínicas deste processo. ${ }^{10,8,11,2,12,13}$ Assim, a HU, uma droga utilizada para o tratamento das neoplasias hematológicas, vem sendo administrada como forma alternativa ao tratamento convencional das doenças falciformes por induzir o aumento da síntese de $\mathrm{Hb} F$ e por não causar efeitos adversos severos em adultos., ${ }^{9,14-17,19}$

Segundo os dados apresentados por Bandeira et al., ${ }^{10}$ pacientes entre 7 e 17 anos de idade, quando receberam o tratamento com HU apresentaram boa resposta clínica com redução do número de internações, bem como de episódios dolorosos e da necessidade transfusional. A utilização da HU em crianças ainda é uma experiência recente e há questionamentos quanto aos benefícios e toxicidade desta droga no organismo infantil, quando utilizada por longo período. ${ }^{19}$ Deste modo, a proposta deste estudo foi de avaliar por meio da revisão literária, a mielotoxicidade na população pediátrica bem como contribuição da HU na melhoria da qualidade de vida dos portadores dessa hemoglobinopatia.

\section{Fisiopatologia da anemia falciforme e fatores moleculares envolvidos}

As conseqüências patológicas dos portadores de anemia falciforme fundamentam-se na polimerização da molécula de $\mathrm{Hb} \mathrm{S}$ induzida por desoxigenação, com conseqüente afoiçamento dos eritrócitos e aumento da viscosidade sanguínea. ${ }^{1} \mathrm{~A}$ anormalidade estrutural desta hemoglobina origina-se por uma mutação no gene da globina beta pela substituição da adenina por timina, codificando valina em lugar de ácido glutâmico na sexta posição da sequiência de aminoácidos que compõe a cadeia polipeptídica beta ( $\beta$ ). A Hb S no estado de baixa tensão de oxigênio sofre modificação em sua molécula devido à interação de natureza hidrofóbica da valina com a fenilalanina da posição 85 e com a leucina da posição 88, desencadeando assim a formação de polímeros num processo de nucleação e criando uma estrutura multipolimérica.,20 A cinética de falcização depende do grau de desoxigenação, concentração intracelular de hemoglobina $S$ e presença ou ausência de Hb F. Essas alterações físico-químicas, além de deformar e enrijecer a membrana celular, ocasionam o fenômeno patológico de vaso-oclusão por predisporem os eritrócitos falcêmicos a aderirem ao endotélio vascular. As células irreversivelmente falcizadas formadas em decorrência do afoiçamento, são removidas e destruídas tanto no meio extravascular como intravascularmente, encurtando assim a sua sobrevida média eritrocitária para cerca de 17 dias, contribuindo desse modo para o agravamento da anemia.

Dados clínicos mais relevantes consistem na susceptibilidade aumentada às infecções, atraso do crescimento e recorrentes crises vaso-oclusivas dolorosas, levando a um dano orgânico isquêmico crônico. As características clíni- cas desta doença somente podem ser percebidas após a estabilização da produção das globinas beta, fato que ocorre por volta do sexto mês de vida. ${ }^{2}$

\section{Aderência celular no endotélio vascular}

Estudos documentam que na anemia falciforme as diferentes moléculas de adesão localizadas nas superfícies das hemácias, leucócitos e plaquetas estão envolvidas na oclusão vascular e são apontadas como sendo um dos possíveis fatores que contribuem nas crises vaso-oclusivas. ${ }^{21,7,22,23,24}$ Segundo Styles et al., ${ }^{24}$ os receptores de adesão VLA-4 e CD36 expressos em reticulócitos, e molécula de adesão VCAM-125 localizada em célula endotelial, participam ativamente no processo de aderência dos eritrócitos falcizados na parede vascular. Recentemente observou-se que a fosfatidilserina (PS), uma molécula de adesão expressa em superfícies das hemácias e plaquetas, é a principal determinante da adesão dos eritrócitos alterados na anemia falciforme, e a intensidade da expressão de PS parece estar diretamente correlacionada com o risco de acidente vascular cerebral (AVC). ${ }^{22}$ Há ainda correlação direta entre PS exposta sobre as células falciformes e a geração de trombina, acentuando assim o episódio vaso-oclusivo. Além dessas, outra molécula de adesão, a anexina $\mathrm{V}^{6}$ expressa em eritrócitos, e um vasoconstritor, a endotelina-1,,$^{21,26}$ parecem estar também correlacionados com a gravidade da doença. A trombospondina (participa na aderência de CD36 à célula endotelial), fator de von Willebrand, laminina, fibrinogênio e fibronectina presentes no plasma e na matriz endotelial são mediadores da adesão das hemácias falcizadas ao endotélio vascular. ${ }^{20,27,28,2,29}$

\section{Fatores genéticos}

Estudos prévios têm documentado a ocorrência de variações nas concentrações de $\mathrm{Hb}$ F entre os pacientes com doença falciforme que nunca fizeram o uso de $\mathrm{HU}$, assim como há registros da associação inversa da gravidade clínica com os níveis de Hb F. Essas variações são determinadas pelos fatores genéticos, principalmente pela persistência hereditária de hemoglobina fetal (PHHF) e haplótipos associados ao gene da Hb S. ${ }^{30,7,20,4,2,31}$ A PHHF pode ser causada por mutação de ponto ou por deleção do cluster $\beta$-simile que resulta em produção significativamente elevada de $\mathrm{Hb}$ F durante a vida adulta. ${ }^{32}$ Esta situação, quando herdada em concomitância com o gene da Hb S, confere melhor prognóstico à doença.

Têm sido identificados cinco diferentes haplótipos associados ao gene da $\mathrm{Hb} \mathrm{S},{ }^{30}$ denominados de Asiático (ou Indiano), Senegal, Benin, Banto (ou CAR - República Centro-Africana) e Camarões. ${ }^{20,2} \mathrm{~A}$ importância dos haplótipos da mutação $\beta^{\text {S }}$ em pacientes com anemia falciforme supõese estar relacionada à gravidade e à evolução clínica da doença, ${ }^{2,9}$ sugerindo melhores prognósticos para os haplótipos 
Senegal e Asiático cuja expressão fenotípica de Hb F mostra-se elevada, e pior evolução clínica para os pacientes portadores dos haplótipos CAR e Benin. ${ }^{33}$

\section{Hidroxiuréia - farmacologia e eficácia clínica}

A HU, em uso desde os $1960,{ }^{2}$ considerada como um agente citotóxico, mutagênico, recombinogênico e antineoplásico, atua na fase $\mathrm{S}$ do ciclo celular com ação específica na ribonucleotídeo redutase, interferindo assim na conversão de ribonucleotídeos em desoxirribonucleotídeos e impedindo a divisão celular. . $^{34,11,35,36,37,13}$

Inúmeros estudos têm reportado a eficácia da HU em portadores de anemia falciforme por conduzir à melhora clínica e hematológica pela redução da incidência de episódios vaso-oclusivos. A droga é indicada para pacientes, incluindo crianças, com três ou mais episódios de crises vasooclusivas com necessidade de atendimento médico; uma crise torácica aguda recidivante; uma ou mais acidentes vasculares encefálicos; priapismo recorrente e anemia grave e persistente, nos últimos 12 meses. ${ }^{14,38}$

Estudo prévio mostrou que a HU tem efeitos múltiplos sobre a linhagem eritrocitária, isto é, promove elevação no nível de $\mathrm{Hb} \mathrm{F}$ em cerca de $60 \%$ dos pacientes tratados, eleva a taxa de hemoglobina, do VCM (volume corpuscular médio) e reduz o número de reticulócitos. ${ }^{22,39} \mathrm{~A}$ concentração da $\mathrm{Hb} \mathrm{F}$ apresenta correlação com redução das crises dolorosas durante o tratamento. Em portadores de anemia falciforme, a redução na taxa de hemoglobina total associada à acentuada reticulocitose caracteriza a gravidade da anemia hemolítica, assim a redução no nível de reticulócitos durante o tratamento, sugere a redução na hemólise. ${ }^{30}$ Outra resposta favorável deste agente terapêutico tem sido a diminuição da expressão de moléculas de adesão tais como fosfatidilserina da superfície eritrocitária e plaquetária, a anexina $\mathrm{V}$, bem como a diminuição das proteínas receptoras localizadas em células endoteliais, contribuindo desse modo para a redução das crises vaso-oclusivas. ${ }^{22}$

Styles et $\mathrm{al}^{24}$ fizeram o primeiro relato relacionando a terapia de HU com a diminuição na expressão de receptores de adesão, destacando a redução significativa de VLA-4 e de CD36 e melhora de eventos vaso-oclusivos. O mecanismo pelo qual esta droga atua na expressão do receptor de adesão é desconhecido. Muitos pacientes têm demonstrado melhora clínica antes do aumento significativo da $\mathrm{Hb}$ F, sugerindo que o efeito benéfico da hidroxiuréia não se limita somente na indução da elevação de Hb F.,25

A administração de hidroxiuréia em crianças falcêmicas tem sido extremamente útil, visto que a terapia transfusional por longo prazo pode trazer riscos de sobrecarga de ferro, aloimunizações e transmissão de infecções virais.9,40 Ainda, tem reduzido em $80 \%$ a freqüência de transfusão sangüínea na população pediátrica além de prevenir potencialmente a lesão de órgãos. ${ }^{12,13}$ Os estudos de coorte envol- vendo crianças e adolescentes têm apontado que as eficácias hematológicas, as respostas da $\mathrm{Hb} \mathrm{F}$ e as toxicidades a este agente quimioterápico são dose dependentes. ${ }^{41,42,43}$ Esta avaliação suscita maior atenção ao escalonamento da dose de HU à dose máxima tolerada (DMT) para maximizar o efeito terapêutico. A eficácia hematológica de HU observada pela prescrição de DMT inclui aumento significativo de nível de hemoglobina, de VCM e de Hb F, além da diminuição de reticulócitos bem como de bilirrubina sérica, associada à mielotoxicidade aceitável. ${ }^{42,32,43}$

Ware et al. ${ }^{42}$ definiram a DMT como $2,5 \mathrm{mg} / \mathrm{kg}$ abaixo daquela que conduziu à ocorrência de duas toxicidades hematológicas sucessivas ou como aquela dose escalonada de HU que atingiu $30 \mathrm{mg} / \mathrm{kg}$ com toxicidade aceitável e sua manutenção por oito semanas.

Vários autores reportam que a terapia por longo prazo com HU à DMT em dose variável de $20 \mathrm{mg} / \mathrm{kg} / \mathrm{dia}$ a $35 \mathrm{mg} / \mathrm{kg} /$ dia foi bem tolerada por pacientes pediátricos. ${ }^{8,44,39,45,16,12}$ Scott et al., ${ }^{13}$ acompanharam 13 crianças entre 10 e 17 anos de idade que receberam inicialmente $10 \mathrm{mg}$ a $20 \mathrm{mg} / \mathrm{kg} / \mathrm{dia}$ de HU por um período médio de dois anos e verificaram que houve aumento na taxa de hemoglobina total com significativa redução nos níveis de reticulócitos e bilirrubina sérica indicando desse modo a redução do processo hemolítico, melhora no curso da doença e maior expectativa de vida em crianças. Em estudos realizados por Bandeira et al. ${ }^{10}$ e Ferster et al., ${ }^{8}$ seis crianças entre 7 a 17 anos de idade, tratadas com dose inicial de $10 \mathrm{mg} / \mathrm{kg} / \mathrm{dia}$ de HU e dose máxima de $25 \mathrm{mg} / \mathrm{kg} /$ dia, e outras 22 crianças (2 a 20 anos de idade) com dose inicial de $20 \mathrm{mg} / \mathrm{kg} /$ dia apresentaram boa resposta clínica com redução do número de internações e dos episódios dolorosos e da necessidade transfusional.

A despeito de vários relatos de benefícios obtidos por este agente terapêutico, há registro de que, em pelo menos $25 \%$ dos pacientes, ${ }^{46}$ a $\mathrm{HU}$ tem demonstrado falha no aumento de concentração de $\mathrm{Hb} \mathrm{F}$, tornando assim necessária a utilização de outras drogas em pacientes refratários à HU. Deste modo, agentes como butirato e derivados, ou ácidos orgânicos de cadeia curta como ácido valpróico, ${ }^{2}$ bem como inibidor de DNA metiltransferase (DNMT) ${ }^{46}$ que também induzem ao aumento da $\mathrm{Hb}$ F, encontram-se em estudos para eventual uso nestes pacientes. Grandes doses de eritropoetina e ferro associado à HU também parecem aumentar substancialmente os níveis de $\mathrm{Hb} \mathrm{F}^{4}$

\section{Toxicidade da droga}

As reações adversas causadas pela $\mathrm{HU}$ incluem mielossupressão, perturbação gastrointestinal, erupção cutânea, enxaqueca, potencial teratogênico e possível carcinogênese. ${ }^{7,11,13}$

Entre população pediátrica há relatos de surgimento de mielotoxicidade, principalmente plaquetopenia e 
neutropenia, durante o uso da medicação, porém, na sua maioria reversível após suspensão da droga. ${ }^{11,47,13,48}$ Durante o tratamento não foi registrado hipodesenvolvimento somático e nenhum comprometimento puberal, pois cada criança pareceu seguir sua curva de crescimento previamente estabelecida. ${ }^{12,13,43}$

A mielotoxicidade para crianças tem sido caracterizada como nível de hemoglobina menor que $5 \mathrm{~g} / \mathrm{dl}$ ou quando ocorrer redução de $20 \%$ em relação à concentração de hemoglobina basal, neutrófilos menor que 2,0 x 10\% /l, contagem reticulocitária menor que $80 \times 10^{9} / \mathrm{l}$ e plaquetas inferior a $80 \times 10^{9} / l^{22,43}$

A HU tem sido empregada para o tratamento de doenças mieloproliferativas e tumores sólidos por tratar-se de um composto que inibe o DNA. ${ }^{37}$ Entretanto, o seu potencial carcinogênico e mutagênico associada à exposição por longo prazo ainda não está estabelecido. Muitas investigações vêm sendo empreendidas para avaliar a mutação e outros danos causados ao DNA somático. Os estudos sugerem que o efeito da mutagenicidade e a carcinogênese de exposição à HU in vivo é baixa embora alguns pacientes com doença mieloproliferativa apresentem risco aumentado de transformação leucêmica quando expostos à esta droga. $.11,49$ Sakano et al., ${ }^{37}$ sugerem que este quimioterápico induz à oxidação de base de DNA como maior via de modificação e à depurinização como menor via, considerando desse modo que a HU participa não somente como atividade anticâncer, mas também como carcinogênese. O teste de genotoxicidade e avaliação da análise de expressão de gene após o tratamento químico por curto prazo denotam a possibilidade de que a HU seja genotóxica e supõem que este efeito possa estar relacionado à concentração da droga. ${ }^{50,51,52,53}$ A exposição prolongada (30 meses) à HU em 17 crianças com anemia falciforme tem revelado mutações somáticas no DNA equivalente aos pacientes com menor período de exposição (7 meses) à droga. Porém, crianças com doença falciforme em terapia com HU, tiveram um número significativamente mais alto de mutações quando comparado com crianças sem exposição à HU. Outro evento verificado em ensaios clínicos relacionados à utilização de HU tem sido o aumento da recombinação gênica, interlocus $\mathrm{V} \gamma-\mathrm{J} \beta$-receptor célula T. Esta recombinação anômala, embora não esteja diretamente relacionada à transformação leucêmica, pode afetar outros genes pela deleção de DNA ou pela translocação cromossomal e desenvolver um risco neoplásico. ${ }^{11,37}$

O tratamento com HU por longo prazo parece possível, efetivo e destituído de qualquer toxicidade que impeça a sua utilização, ${ }^{44,32,11,45}$ sendo bem tolerada por pacientes pediátricos durante sete anos de terapia. ${ }^{7,23,49,54,43}$

\section{Considerações finais}

O uso de hidroxiuréia em crianças portadoras de anemia falciforme tem proporcionado redução de suas compli- cações clínicas e aumento significativo na expectativa de vida destes pacientes.

A terapia tem garantido eficácia clínica durante alguns anos de tratamento em população pediátrica, reduzindo o número de internações e dias de hospitalização.

Embora a droga apresente efeitos altamente benéficos em curto prazo, elevando os níveis de hemoglobina fetal, reduzindo hemólises e crises vaso-oclusivas, requer atenção e investigação cuidadosa quanto às possíveis ações genotóxicas, pois pode causar alterações irreversíveis no material genético, com sérias conseqüências ao organismo. A HU é considerada como melhor opção terapêutica atualmente disponível na obtenção da melhora clínica e hematológica, porém o desafio para o risco carcinogênico permanece e, para alcançar resposta segura para esta questão, ainda requer longo período de acompanhamento de grande número de pacientes com anemia falciforme. Outras drogas possuidoras de eficácia terapêutica similar a HU vêm sendo pesquisadas, havendo, portanto, possibilidade de futuramente vir a ser substituída por outra droga destituída de potencial carcinogênico.

\begin{abstract}
Sickle cell anemia is a genetic disease characterized by a high morbimortality rate, it is considered as the most serious among all sickle cell diseases. The most effective therapeutic options available nowadays for the treatment of this hemoglobinopathy are bone morrow transplantation (BMT) and hydroxyurea (HU). $B M T$ is considered a high risk procedure due to the different complications and significant mortality rates. The use of $\mathrm{HU}$ for children with sickle cell anemia has reduced the clinical complications and given a significant increase in life expectancy by augmenting the fetal hemoglobin levels and hemoglobin concentrations and reducing cytomegalovirus, as well as reducing hemolysis and vaso-occlusive events. Thus, $\mathrm{HU}$ is considered the best therapeutic option currently available. However, as HU has been identified as a potentially carcinogenic drug, there are questions related to the benefits and toxicities when it is used over long periods of time. This work aimed at evaluating, through a review of the literature, the risks, benefits and adverse effects of the use of hydroxyurea in children. Rev. bras. hematol. hemoter. 2006;28(2):144-148.
\end{abstract}

Key words: Sickle cell anemia; hydroxyurea; pediatric population.

\section{Referências Bibliográficas}

1. Embury, S.H. Anemia Falciforme e Hemoglobinopatias Associadas. In: Bennett, J.C. \& Plum, F. Cecil Tratado de Medicina Interna. Rio de Janeiro: Guanabara Koogan, cap.137,p.976-988, 1997.

2. Naoum PC. Interferentes eritrocitários e ambientais na anemia falciforme. Rev Bras Hematol Hemoter 2000;22(1):5-22.

3. Silva RBP, et al. A anemia falciforme como problema de Saúde Pública no Brasil. Rev Saúde Pública 1993;27(1):54-58.

4. Manual de Diagnóstico e Tratamento de Doenças Falciformes. Brasília: Agência Nacional de Vigilância Sanitária - Anvisa, 2002. 
5. Programa de Anemia Falciforme do Ministério da Saúde - Brasília, 1996. 6. Di Nuzzo DVP, Fonseca SF. Anemia falciforme e infecções. Jornal de Pediatria 2004;80(5):347-354.

7. Buchanan GR, et al. Sickle Cell Disease. American society of Hematology 2004; 35-47.

8. Ferster A, et al. Five years of experience with hydroxyurea in children and young adults with sickle cell disease. Blood 2001;97(11):3.628-3.632.

9. Schnog JB, et al. Sickle cell disease; a general overview. The Journal of Medicine 2004;62(10):364-374.

10. Bandeira FMGC, et al. Hidroxiuréia em pacientes com síndromes falciformes acompanhados no Hospital Hemope, Recife, Brasil. Rev Bras Hematol Hemoter 2004;26(3):189-194.

11. Hanft VN, et al. Acquired DNA mutations associated with in vivo hydroxyurea exposure. Blood 2000;95(11):3.589-3.593.

12. Rogers ZR. Hydroxyurea therapy for diverse pediatric populations with sickle cell disease. Seminars in Hematology 1997;34(3):42-47.

13. Scoot JP, et al. Hydroxyurea therapy in children severely affected with sickle cell disease. Journal of Pediatrics 1996;128(6): 820-828.

14. Costa FF. Anemia falciforme. In: Zago MA, Falcão RP, Pasquini R. Hematologia: Fundamentos e Prática. São Paulo: Atheneu, cap.30, p.305, 2001.

15. Kratovil T, et al. Hydroxyurea therapy lowers TCD velocities in children with sickle cell disease. Pediatric Blood \& Cancer. Published online: 8 Mar, 2006.

16. Montalembert $\mathrm{M}$, et al. Long-term hydroxyurea treatment in children with sickle cell disease: tolerance and clinical outcomes. Haematologica 2006; 91(1):125-128.

17. Rotter M, et al. Molecular crowding limits the role of fetal hemoglobin in therapy for sickle cell disease. J Mol Biol 2005;347:1.015-1.023.

18. Venigalla P, et al. A patient on hydroxyurea for sickle cell disease who developed an opportunistic infection. Blood 2002;100(1): 363.

19. Meyappan JD, et al. Parents' assessment of risk in sickle cell treatment with hydroxyurea. J Pediatr Hematol Oncol 2005;27(12):644-650.

20. Galiza Neto GC, Pitombeira MS. Aspectos moleculares da anemia falciforme. Jornal Brasileiro de Patologia e Medicina Laboratorial 2003;39(1):51-56.

21. Brun M, et al. Hydroxyurea downregulates endothelin-1 gene expression and upregulates ICAM-1 gene expression cultured human endothelial cells. Pharmacogenomics J 2003;3(4):215-226.

22. Covas DT, et al. Effects of hydroxyurea on the membrane of erythrocytes and platelets in sickle cell anemia. Haematologica 2004;89(3):273-280.

23. Gulbis B, et al. Hydroxyurea for sickle cell disease in children and for prevention of cerebrovascular events: the Belgian experience. Blood 2005; 105(7):2.685-2.690.

24. Styles LA, et al. Decrease of very late activation Antigen-4 and CD36 on reticulocytes in sickle cell patients treated with hydroxyurea. Blood 1997; 89(7):2.554-2.559.

25. Stuart A, et al. Insights into elevated distortion product otoacoustic emissions in sickle cell disease: Comparisons of hydroxyurea-treated and non-treated young children. Hearing Research 2006;212:83-89.

26. Lapoumeroulie C, et al. Decrease plasma endothelin-1 levels in children with sickle cell disease treated with hydroxyurea. Haematologica 2005;90(3):401-403.

27. Gupta K, et al. Mechanism of interaction of thrombospondin with human endothelium and inhibition of sickle erythrocyte adhesion to human endotelial cells by heparin. Biochim Biophys Acta1999;1453:63-73.

28. Lee SP, et al. Sickle cell adhesion to laminin: potencial role for the 5 chain. Blood 1998;92:2.951-2.958.

29. Wick TM, et al. Unusually large von Willebrand factor multimers increase adhesion of sickle erythrocytes to human endothelial cells under controlled flow. J Clin Invest 1987;80:905-907.

30. Andrade SR, et al. Características hematológicas e bioquímicas da doença falciforme no estado do Rio Grande do Norte. Rev Bras Anál Clín 2001; 33(4): 205-210.

31. Vicari P, et al. Effects of hydroxyurea in a population of Brazilian patients with sickle cell anemia. American Journal of Hematology 2005;78(3): 243-244.
32. Zago MA. Defeitos hereditários das hemoglobinas. In: Zago MA, Falcão RP, Pasquini R. Hematologia Fundamentos e Prática. São Paulo: Atheneu, cap.29,p.279-287, 2001.

33. Powars RD. $\beta^{\text {s }}$-gene-cluster haplotypes in sickle cell anemia. In: Nagel RL (ed.). Hematology/Oncology Clinics of North America - Hemoglobinopathies 1991;5(3):475-93.

34. Galli A, Schiestl RH. Hydroxyurea induces recombination in diiding but not in G1 or G2 cell cycle arrested yeast cells. Mutat Res 1996; 354(1):69-75.

35. Lima PDL, et al. Evaluation of the mutagenic activity of hydroxyurea on the G1-S-G2 phases of the cell cycle: an in vitro study. Geneties and Molecular Research 2003;2(3):328-333.

36. Rang HP, et al. Farmacologia. $4^{a}$ ed. São Paulo: Ganabara Koogan. cap.42, p.571, 2000.

37. Sakano K, et al. Hydroxyurea induces site-specific DNA damage via formation of hydrogen peroxide and nitric oxide. Jpn J Cancer Res 2001; 92(11):1.166-1.174.

38. Ministério da Saúde, Portaria n 872 de 12 de Novembro de 2002. Art. $1^{\circ}$ - Protocolo Clínico e Diretrizes Terapêuticas - Doença Falciforme Hidroxiuréia. Secretário Renilson Rehem de Souza.

39. Kinney TR, et al. Safety of hydroxyurea in children with sickle cell anemia: Results of the HUG - KIDS Study, a Phase I/II Trial. Blood 1999;94(5):1.550-1.554.

40. Ware RE, et al. Prevention of secondary stroke and resolution of transfusional iron overload in children with sickle cell anemia using hydroxyurea and phlebotomy. J Pediatr 2004;145(3):346-352.

41. Hankins JS, et al. Long-term hydroxyurea therapy for infants with sickle cell anemia: the HUSOFT extension study. Blood 2005;106(7): 2.269-2.275.

42. Ware RE, et al. Prevention of secondary stroke and resolution of transfusional iron overload in children with sickle cell anemia using hydroxyurea and phlebotomy. J Pediatr 2004;145(3):346-352.

43. Zimmerman SA, et al. Sustained long-term hematologic efficacy of hydroxyurea at maximum tolerated dose in children with sickle cell disease. Blood 2004;103(6): 2.039-2.045.

44. Ferster A, et al. Five years of experience with hydroxyurea in children and young adults with sickle cell disease. Blood 2001;97(11):3.628-3.632.

45. Maier-Redelsperger M, et al. Fetal hemoglobin and F-cell responses to long-term hydroxyurea treatment in young sickle cell patients. Blood 1998; 91(12):4.472-4.479.

46. Lavelle DE. The molecular mechanism of fetal hemoglobin reactivation. Semin Hematol 2004;41(4):3-10.

47. Hoppe C, et al. Use of hydroxyurea in children aged 2 to 5 years with sickle cell disease. J Pediatr Hemat Onco 2000;22:330-334.

48. Sumoza, A. et al. Hydroxyurea (HU) for prevention of recurrent stroke in sickle cell anemia (SCA). Am J Hematol 2002;71:161-165.

49. Montalembert M, Davis SC. Is hydroxyurea leukemogenic in children with sickle cell disease? Blood 2001;98(9):2.878-2.879.

50. Hu T, et al. Identification of a gene expression profile that discriminates indirect-acting genotoxins from direct-acting genotoxins. Mutat Res 2004; 549(1-2): 5-27.

51. Lee M, et al. Enhanced prediction of potential rodent carcinogenicity by utilizing comet assay and apoptotic assay in combination. Mutat Res 2003; 54(1-2):9-19.

52. Sarachek A, et al. Genetic destabilization of Candida albicans by hydroxyurea. Microbios 1991;65(262):39-61.

53. Severin I, et al. Toxic interaction between hydroxyurea and 1-beta-Darabinofuranosylcytosine on the DNA of a human hepatoma cell line (HEPG2). Toxicol Lett 2003;145(3):3.003-311.

54. Torres AF, et al. Effect of hydroxyurea on hemoglobin S. Medicina 2003; 63(2): 140-142.

Avaliação: Editor e dois revisores externos.

Conflito de interesse: não declarado

Recebido: 12/11/2005

Aceito após modificações: 20/05/2006 